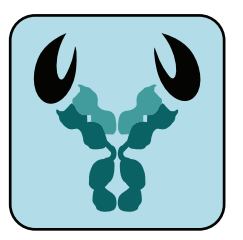

Journal of Experimental \&

Clinical Cancer Research

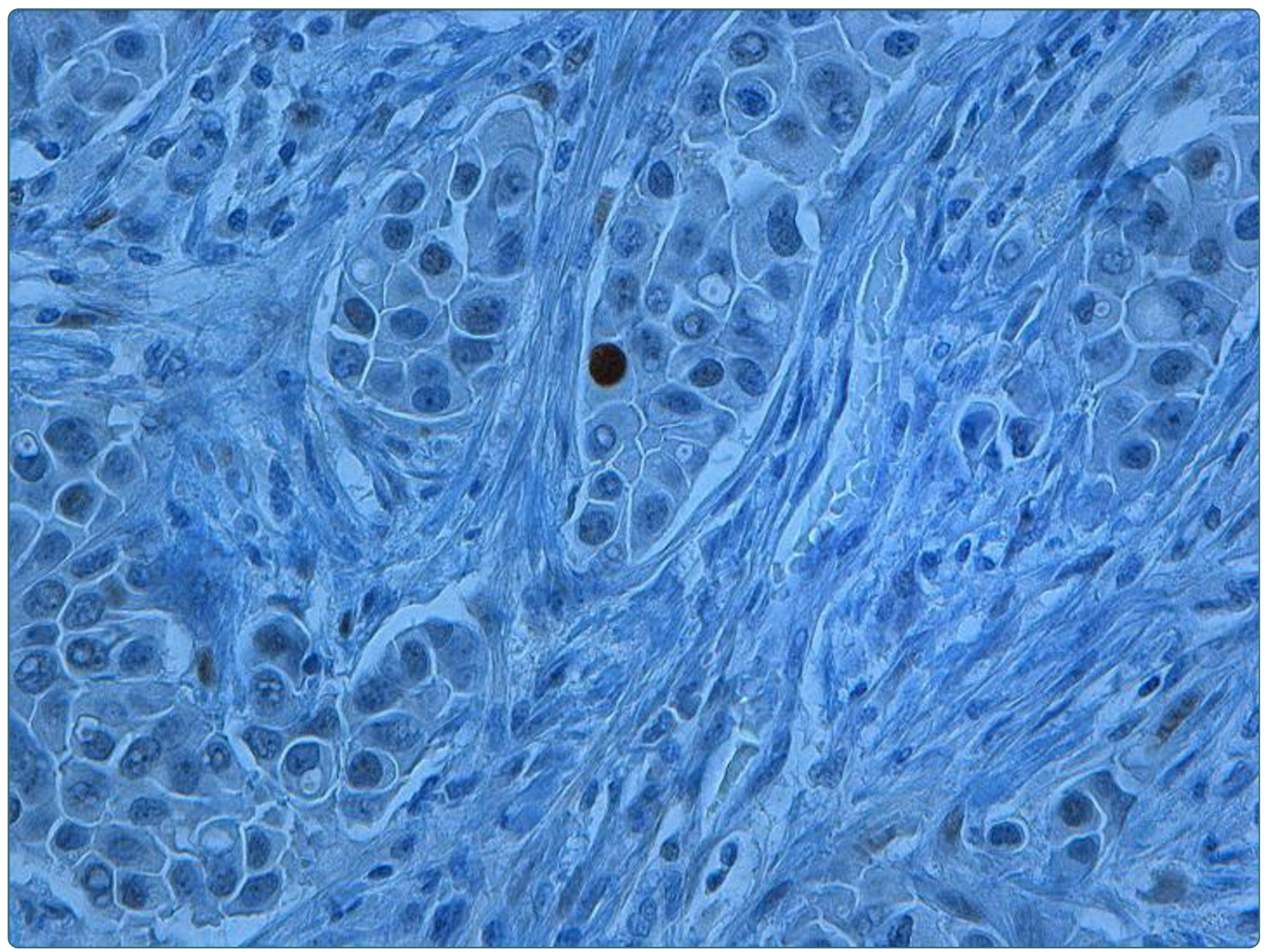

\title{
Evaluation of HER2 and p53 expression in predicting response to docetaxel-based first-line chemotherapy in advanced breast cancer
}

Camerini et al. 


\title{
Evaluation of HER2 and p53 expression in predicting response to docetaxel-based first-line chemotherapy in advanced breast cancer
}

\author{
Andrea Camerini ${ }^{*}$, Sara Donati ${ }^{1}$, Paolo Viacava ${ }^{2}$, Olimpia Siclari ${ }^{1}$, Cheti Puccetti ${ }^{1}$, Gianna Tartarelli ${ }^{1}$, \\ Chiara Valsuani', Filomena De Luca ${ }^{2}$, Leonardo Martini ${ }^{2}$, Andrea Cavazzana ${ }^{3}$ and Domenico Amoroso ${ }^{1}$
}

\begin{abstract}
Background: The human epidermal growth factor receptor 2 (HER2) and p53 pathways may be involved in chemotherapy sensitivity and/or resistance. We explore the value of HER2 and p53 status to foretell docetaxel sensitivity in advanced breast cancer.
\end{abstract}

Methods: HER2 and p53 expression was analysed in 36 (median age 55 yrs; range 37-87) metastatic breast cancer patients receiving docetaxel-based first-line chemotherapy. HER2 was determined by immunohistochemistry (IHC) and fluorescence in situ hybridization (FISH), p53 was tested by IHC. We correlate the expression of study parameters with pathologic parameters, RECIST response and survival. The standard cut-off value of 2 was used to determine HER2 overexpression while p53 mean expression level was used to divide low/high expressors tumors.

Results: Median time to progression and overall survival were 9 (range 2 - 54) and 20 (range 3 - 101) months. Overall response rate was 41.6\%. Nine cases showed HER2 overexpression. HER2 was more frequently overexpressed in less differentiated $(p=0.05)$ and higher stage $(p=0.003)$ disease. Mean FISH-HER2 values were significantly higher in responder than in non-responder pts (8.53 \pm 10.21 vs $2.50 \pm 4.12, p=0.027)$. Moreover, HER2 overexpression correlates with treatment response at cross-tabulation analysis $(p=0.046)$. p53 expression was only associated with higher stage disease $(p=0.02)$ but lack of any significant association with HER status or docetaxel response. No significant relation with survival was observed for any parameter.

Conclusion: Our data seem to indicate that FISH-determined HER2 status but not p53 is associated with docetaxel sensitivity in metastatic breast cancer.

\section{Background}

Breast cancer (BC) is the leading cause of cancer and the second leading cause of cancer death in women in the USA [1] and its incidence is increasing in many countries, including Italy [2] thus representing a major health problem. To date, the role of chemotherapy in $\mathrm{BC}$ treatment is certain and taxanes are widely used in both early and advanced setting [3,4] but we have no validated sensitivity and/or resistance predictive factor and, hence, the search for a taxane-specific predictive marker is an hot topic. Colled as the "guardian of the

\footnotetext{
* Correspondence: andreacamerini@katamail.com

'Oncology Department, Medical Oncology Division, AUSL12 di Viareggio and

Istituto Toscano Tumori - Versilia Hospital, Lido di Camaiore, Italy

Full list of author information is available at the end of the article
}

genome" [5] and the "cellular gatekeeper" [6], the p53 protein acts as cell modulator by driving lots of stressinducing signals to different antiproliferative cellular responses [7]. p53 can be activated in response to DNA damage (such as cytotoxic agents), oncogene activation or hypoxia resulting to cellular outputs such as apoptosis, cell-cycle arrest, senescence, or modulation of autophagy [8-10]. Although about $50 \%$ of BCs harbours TP53 gene mutations [11,12], the biological role and clinical importance of p53 alterations in BC are still unclear. This maybe related to the very complicated and extensive p53 network and to technical problems associated with surrogate markers to identify TP53 gene defects, as most detection tests lack sensitivity and specificity. Despite its limits, immunohistochemical p53 detection

\section{Biomed Central}


demonstrated in numerous studies to be a prognostic factor in $\mathrm{BC}$ [11-17] and that it may determine the sensitivity to specific therapeutic agents [18-22]. Some evidences may indicate that abnormal p53 expression could be associated with taxane sensitivity but its specific predictive role is unclear [22-24].

Another leading cell growth regulator in $\mathrm{BC}$ is the human epidermal growth factor receptor (HER) 2 (HER2; erbB2/neu). The HER2 oncogene encodes one of four trans-membrane receptors within the erbB family. Its over-expression, which occurs in approximately $25 \%$ of all breast cancer tumors, is associated with a shortened disease-free interval and poor survival [25]. HER2 blockage in preclinical models of human $\mathrm{BC}$ and in primary breast tumors from women treated with HER2targeted therapies leads to the inhibition of survival pathways, which in turn induces tumor cell apoptosis [26]. The clinical benefit of HER2 inhibition by its specific monoclonal antibody trastuzumab is meaningful in both early and advanced disease [27,28]. HER2 status may also influence chemotherapy sensitivity as proposed by Gennari et al [29] that focused on the adjuvant setting showing that the added benefits of adjuvant chemotherapy with anthracyclines seems to be reserved to breast cancer harboring HER2 overexpression or amplification.

On this grounds, we analysed the relationship between HER2 and p53 expression and response to first-line docetaxel based chemotherapy in advanced BC finding that FISH-determined HER2 status but not p53 could predict docetaxel sensitivity.

\section{Methods}

\section{Patient characteristics and tissue samples}

Tumor samples were obtained from breast cancer patients who underwent surgery at Versilia Hospital in Lido di Camaiore (Italy) from 2000 to 2004. A total of 36 breast cancer patients (median age 55 yrs; range 3787) receiving between 2001 and 2005 a docetaxel-based first-line chemotherapeutic regimen for metastatic disease were retrospectively selected for the study. Study population characteristics are shown in table 1 . Mean time from initial diagnosis to first relapse was $15.8 \pm$ 6.5 months. Location of metastatic deposits includes bone (21/36), liver (21/36), lung (16/36), lymphnodes $(14 / 36)$ and local recurrence (3/36) with 27 out of 36 patients presenting with multiple disease sites; remaining 9 patients with single-site metastasis presented with measurable non-bone disease. Patients receiving preoperative chemotherapy, having a family history of breast cancer or receiving docetaxel as part of adjuvant treatment were excluded as well as those for whom follow-up data were missing. Adjuvant treatment was performed in all patients but two as follow: 18 patients
Table 1 Study population characteristics $(n=36)$

\begin{tabular}{|c|c|}
\hline Median [range] age (yr) & $55[37-87]$ \\
\hline \multicolumn{2}{|l|}{ Histotype $^{\#}$} \\
\hline Invasive ductal carcinoma & $28(77.7 \%)$ \\
\hline Invasive lobular carcinoma & $5(13.8 \%)$ \\
\hline Mixed (ductal and lobular) & $2(5.5 \%)$ \\
\hline Undifferentiated & $1(3.0 \%)$ \\
\hline \multicolumn{2}{|l|}{ Grading $^{\circ}$} \\
\hline G2 & $21(58.3 \%)$ \\
\hline G3 & $15(41.7 \%)$ \\
\hline \multicolumn{2}{|l|}{ ER status } \\
\hline Negative & $14(38.8 \%)$ \\
\hline Positive & $22(61.2 \%)$ \\
\hline \multicolumn{2}{|l|}{ PgR status } \\
\hline Negative & $13(36.1 \%)$ \\
\hline Positive & $23(63.9 \%)$ \\
\hline \multicolumn{2}{|l|}{ HER2 status* } \\
\hline Negative & $27(75.0 \%)$ \\
\hline Positive & $9(25.0 \%)$ \\
\hline \multicolumn{2}{|l|}{ Adjuvant chemotherapy^ } \\
\hline FEC & $18(52.9 \%)$ \\
\hline EC & $11(32.4 \%)$ \\
\hline CMF & $5(14.7 \%)$ \\
\hline Mean \pm SD time to first relapse (months) & $15.8 \pm 6.5$ \\
\hline \multicolumn{2}{|l|}{ Metastatis sites } \\
\hline Bone & $21(58.3 \%)$ \\
\hline Liver & $21(58.3 \%)$ \\
\hline Lung & $16(44.4 \%)$ \\
\hline Lymphnodes & $14(38.8 \%)$ \\
\hline Local & $3(8.3 \%)$ \\
\hline \multicolumn{2}{|l|}{ Chemotherapy" } \\
\hline TXT75 & $14(38.8 \%)$ \\
\hline TXT25 & $8(22.2 \%)$ \\
\hline TXT75+C & $5(13.8 \%)$ \\
\hline TXT75+T & $9(25.2 \%)$ \\
\hline \multicolumn{2}{|l|}{ Treatment best response } \\
\hline Complete response & $1(2.7 \%)$ \\
\hline Partial response & $14(38.8 \%)$ \\
\hline Stable disease & $12(33.3 \%)$ \\
\hline Disease progression & $9(25.2 \%)$ \\
\hline \multicolumn{2}{|l|}{ Time to disease progression (months) } \\
\hline Median [range] & 9 [2-54] \\
\hline \multicolumn{2}{|l|}{ Overall survival (months) } \\
\hline Median [range] & 20 [3-101] \\
\hline
\end{tabular}

\#According to WHO hystological typing of breast tumor (Ref. 32). ${ }^{\circ}$ According to Elston and Ellis classification (Ref. 31). *Pre-study determination. "See text for regimen details. ^on 34 pts.

received an association of 5-fluorouracil (5-FU), epirubucin and cyclophosphamides (FEC) for 6 cycles, 11 patients received an association of epirubucin and cyclophosphamides (EC) for 4 cycles, and remaining 5 patients received an association of cyclophosphamides, methotrexate and 5-FU (CMF) for 6 cycles. 
All patients received docetaxel-based first-line chemotherapy for metastatic disease. In particular, 14 out of 36 patients received six cycles docetaxel $\left(75 \mathrm{mg} / \mathrm{m}^{2}\right)$ every 3 weeks (TXT75), 8 patients received docetaxel $\left(25 \mathrm{mg} / \mathrm{m}^{2}\right)$ on a weekly basis (TXT25), 5 patients received a combination of docetaxel $\left(75 \mathrm{mg} / \mathrm{m}^{2}\right)$ on day 1 plus capecitabine (1000 mg/m $\mathrm{m}^{2}$ bid day $\left.1-14\right)$ every 3 weeks $($ TXT75 + C) and the remaining 9 patients with HER2-positive disease received a combination of docetaxel $\left(75 \mathrm{mg} / \mathrm{m}^{2}\right)$ and trastuzumab $(8 \mathrm{mg} / \mathrm{kg}$ loading dose then $6 \mathrm{mg} / \mathrm{kg}$ ) both on day 1 every 3 weeks $($ TXT75+T) (Table 1). Every treatment was planned for up to 6-9 months. Causes for early treatment stop were unacceptable toxicity, disease progression or patient refusal. Trastuzumab was administered alone after docetaxel discontinuance as maintenance therapy until disease progression in 6 responder patients. Tumor assessment was performed every 3 months by CT-scan and/or chest X-ray coupled with abdomen ultrasound depending on those used at baseline. Time to progression (TTP) was calculated from the date of treatment start to the date of first-documented progression. Overall survival (OS) was defined as the time interval between the start of treatment and death or last followup contact. Treatment response was assessed according to RECIST criteria and we consider as responder a patient achieving a complete (CR) or partial (PR) response to treatment. Patients achieving disease stabilization (SD) or disease progression (PD) were considered as not-responders. Anyway, we planned a secondary analysis considering as responders even patients achieving disease stabilization as best result. Median TTP was 9 (range 2 - 54) months and overall response rate (ORR) was $41.6 \%$ (14 out of 36 ) with 11 and 8 pts experiencing disease stabilization and progression respectively. Median OS was 20 (range 3 - 101) months. Being a retrospective analysis patients were not asked to sign any informed consent; anyway samples were coded and the names of the patients were not revealed. All available clinico-pathological data were collected and stored in an appropriate database. Age, tumor grade and stage [30,31], size, histotype,(32) estrogen receptor (ER) and progesterone receptor (PgR) status were considered.

\section{Immunoistochemistry}

P53 expression was evaluated by immunohistochemistry (IHC) while HER2 expression was evaluated both by IHC and fluorescence in situ hybridization (FISH - see next paragraph). All IHC analyses were performed on routinely processed, formalin-fixed and paraffinembedded tissue samples obtained from primary tumor. For p53 IHC analysis, representative tumor sections $(3 \mu \mathrm{m})$ were deparaffinized, rehydrated and immunostained using antigen retrieval by microwave technique.
After endogenous peroxidase blocking sections were incubated for $45 \mathrm{~min}$ at $37^{\circ} \mathrm{C}$ with a $1: 50$ dilution of primary mouse anti-human $p 53$ monoclonal antibody (clone: DO-7, isotype IgG2b) (Dako), then immunostained with secondary antibodies and finally counterstained with hematoxylin. Sections of known positive mammary carcinoma were used as positive controls. Negative controls were obtained by omitting the primary antibodies. For p53 only a clear nuclear staining in the absence of cytoplasmic background coloration was considered positive. A minimum of 1.000 cells were counted for each tumor and immunoreactivity was expressed as a percentage of positive cells on the total number of tumor cells. A value of $11 \%$ of positive cells, corresponding to the mean value of p53 expressing tumor cells, was used as cut-off to distinguish high and low expressing tumors.

HER2 IHC evaluation was realized by the streptavidinbiotin-peroxidase complex technique (StreptABC, DAKO) as standard for the time of analysis. Tissue sections were deparaffinized and underwent antigenic retrieval and endogenous peroxidase blocking. Sections were first incubated with polyclonal primary antibodies against c-erbB-2 (A0485, DAKO) with a 1:500 dilution, then incubated in secondary biotinylated antibody and finally counterstained with Hematoxylin. Immunohistochemical analyses of c-erbB-2 expression describe the intensity and staining pattern of tumor cells. The FDArecognized test, the Herceptest ${ }^{\mathrm{TM}}$ (DAKO), describes four categories: no staining, or weak staining in fewer than $10 \%$ of the tumor cells $(0)$; weak staining in part of the membrane in more than $10 \%$ of the tumor cells $(1+)$; complete staining of the membrane with weak or moderate intensity in more than $10 \%$ of the neoplastic cells $(2+)$; and strong staining in more than $10 \%(3+)$. Cases with 0 or $1+$ score were regarded as negative; the ones with $3+$ score were regarded as positive while $2+$ cases underwent FISH and categorized accordingly. All immunostained specimens were evaluated by two observers independently ( $\mathrm{PV}$ and $\mathrm{AC}$ ) without knowledge of clinical characteristics and/or follow-up information and the discrepant cases were jointly re-evaluated and agreement was met.

\section{Dual-color Fluorescence in situ Hybridization}

HER2 amplification was analyzed on microdissected tumor samples using FISH HER2 PharmDx (Dako, K5331), which contains both fluorescently-labeled HER2/neu gene and chromosome 17 centromere probes. Microdissection was performed by an expert pathologist different from ones that performed IHC evaluation. In brief, sections were deparaffinized, heat-pretreated in citrate buffer at $80^{\circ} \mathrm{C}$ for near 1 hour, digested with pepsin at room temperature for few minutes and 
dehydrated in graded ethanol. After the HER2/CEN17 probe mix was applied to the dry slides. The slides were then incubated in hybridizer (Hybridizer Instrument for in situ hybridization, DAKO, S2450) for denaturation at $82^{\circ} \mathrm{C}$ for 5 minutes and hybridization at $45^{\circ} \mathrm{C}$ for about 18 hours. The slides were redehydrated in graded ethanol. FISH analyses were performed according to the HER2 FISH PharmDx (Dako) criteria. In each case, 100 non-overlapped, intact interphase tumor nuclei identified by DAPI staining were evaluated, and gene (red signal) and CEN17 (green signal) copy numbers in each nucleus were assessed. The cases were considered to be amplified when the average copy number ratio, HER2/CEN17, was $\geq 2.0$ in all nuclei evaluated or when the HER2 signals formed a tight gene cluster. Among the cases in which the gene was not amplified, samples showing more than four copies of the HER2 gene and more than four CEN17 in more than $10 \%$ of the tumor cells were considered to be polysomic for chromosome 17 .

\section{Statistical analysis}

Correlation between p53, HER2 and other molecular and clinical parameters were assessed by contingency table methods and tested for significance using the Pearson's chi-square test. Mean values were compared using the student-T test. Survival curves were calculated using the Kaplan-Meier method and tested for significance using the log-rank test. Univariate and multivariate relative risks were calculated using Cox proportional hazards regression. Statistical analyses were performed using NCSS software. All tests were two-tailed, and p < 0.05 was considered to be significant.

\section{Results}

Expression levels of p53 ranged from 0\% to 70\% of immunostained nuclei with a mean expression value of $11 \%$ (median $=5 \%$ ) (Figure 1 and 2). Using this mean value as cut-off to distinguish high and low expressing tumors, staining was considered high in 11 (30.5\%) out of 36 tumors in our series (similar results were obtained using as cut-off the median value). P53 expression levels were only related to disease stage with higher p53 levels in higher stage disease $(p=0.02)$ but lack of any significant association with HER2 status, other clinic-pathologic parameters (age, ER and PgR status, Ki67 and tumor grading) or docetaxel response (Table 2). Even comparing mean p53 expression levels between responders vs not-responders patients we did not find any significant difference (not shown) and mean TTP (8.6 \pm 7.0 vs $9.2 \pm 11.9$ months; $p=\mathrm{ns})$ and OS $(21.6 \pm 13.0$ vs $19.8 \pm 10.2$ months; $p=\mathrm{ns}$ ) did not differ between low and high p53 groups. Morever, no significant relation with survival parameters was observed for p53 at Kaplan-Meier analysis.

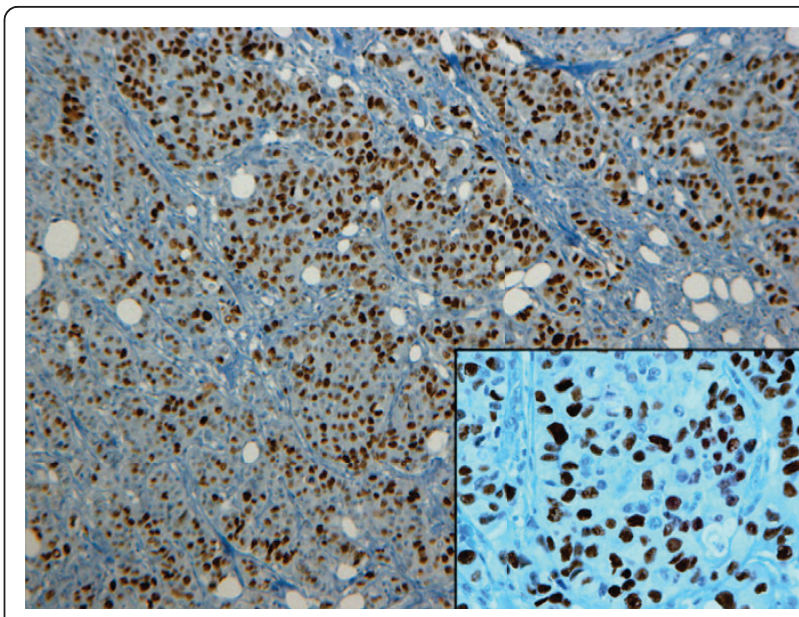

Figure 1 Immunohistochemical positive staining of p53 in a representative case of high-grade (G3) ductal carcinoma.

Immunostaining shows a clear and wide nuclear staining in an high grade (G3) invasive ductal carcinoma. Original magnifications: $\times 100$ (inset $\times 250$ ).

Conversely, HER2 positive breast tumors appear to be, as expected, less differentiated and of higher stage more frequently than negative ones (Table 3 ). In accordance with literature data, 6 out of $9(66.6 \%)$ HER2 positive while only 9 out 27 (33.3\%) HER2 negative patients respectively responded to docetaxel treatment and this difference was significant (Table 3). Confirmatory results were obtained by student-T test on mean FISH values between responders vs not-responders patients. In fact, responder group showed significantly higher mean FISH values than not-responder $(8.53 \pm 10.21$ vs $2.50 \pm 4.12$, $p=0.027)$. All HER2-positive patients received trastuzumab in combination with docetaxel while HER2-negative

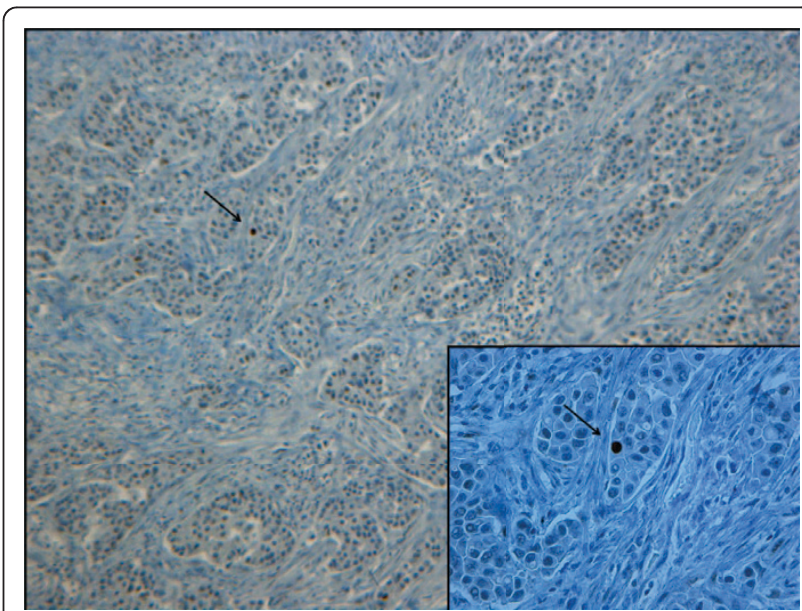

Figure 2 p53 immunohistochemical negative staining in a grade 2 ductal carcinoma. The wide majority of nuclei showed no staining with the exception of one clear positive nucleus (arrow) in the upper left corner. Original magnifications: $\times 100$ (inset $\times 250$ ). 
Table 2 p53 expression in relation to main tumor characteristics and treatment response

\begin{tabular}{|c|c|c|c|c|}
\hline & \multicolumn{4}{|c|}{ p53 expression } \\
\hline & Total & Low & High & $p$ value \\
\hline \multicolumn{5}{|l|}{ Age } \\
\hline$<55$ yrs & 18 & 13 & 5 & n.s. \\
\hline$\geq 55$ yrs & 18 & 12 & 6 & \\
\hline \multicolumn{5}{|l|}{ ER expression } \\
\hline Negative & 14 & 8 & 6 & n.s. \\
\hline Positive & 22 & 17 & 5 & \\
\hline \multicolumn{5}{|c|}{ PgR expression } \\
\hline Negative & 13 & 9 & 4 & n.s. \\
\hline Positive & 23 & 16 & 7 & \\
\hline \multicolumn{5}{|l|}{ Grading $^{\#}$} \\
\hline G2 & 21 & 17 & 4 & n.s. \\
\hline G3 & 15 & 8 & 7 & \\
\hline \multicolumn{5}{|l|}{ Stage ${ }^{* \circ}$} \\
\hline I-IIA & 17 & 15 & 2 & 0.02 \\
\hline IIB-III & 16 & 7 & 9 & \\
\hline \multicolumn{5}{|l|}{ HER2 } \\
\hline Negative" & 27 & 21 & 6 & n.s. \\
\hline Positive" & 9 & 4 & 5 & \\
\hline \multicolumn{5}{|l|}{ Ki67 } \\
\hline Negative & 22 & 15 & 7 & n.s. \\
\hline Positive & 14 & 10 & 4 & \\
\hline \multicolumn{5}{|c|}{ Treatment response } \\
\hline $\mathrm{CR}+\mathrm{PR}$ & 15 & 11 & 4 & n.s. \\
\hline $\mathrm{SD}+\mathrm{PD}$ & 21 & 14 & 7 & \\
\hline
\end{tabular}

n.s. = not significant; $C R=$ complete response; $P R=$ partial response; $S D=$ stable disease; PD = disease progression. *According to Elston and Ellis classification (Ref. 31). *According to UICC-TNM classification of malignant tumours, sixth edition 2002 (Ref. 30). ${ }^{\circ}$ At initial diagnosis time. "IHC 0,1+ and $2+\mathrm{FISH}$ negative were regarded as negative while $\mathrm{IHC} 3+$ or $2+\mathrm{FISH}$ positive were regarded as positive.

ones were treated with docetaxel with a known influence on and response rate and outcome. To shrink the possible treatment-related bias we test the FISH value difference between docetaxel responders and not-responder in HER2-negative subgroup $(n=27)$ so removing trastuzumab treatment-related bias. Taking into account the smaller sample size and the lower FISH values $(<2)$, we found a non-statistically significant difference in mean FISH value with responders patients having higher values $(1.64 \pm 0.157$ vs $1.38 \pm 0.146 ; \mathrm{p}=\mathrm{ns})$. We also performed the same analysis in FISH-positive group (11 pts all receiving docetaxel plus trastuzumab) and we observed also in this small subgroup a similar behaviour (16.86 \pm 9.78 vs $9.85 \pm 10.53$; responders vs not-responders; $\mathrm{p}=$ $0.18 \mathrm{~ns})$.

Mean TTP (positive vs negative: $7.9 \pm 8.1$ vs $9.8 \pm 9.4$ months; $p=0.18 \mathrm{~ns}$ ) and $\mathrm{OS}$ (positive vs negative: $18.1 \pm 11.7$ vs $21.2 \pm 12.1$ months; $p=0.12 \mathrm{~ns}$ ) showed a only modest trend towards significance with HER2 positive patients having worse prognosis. Kaplan-Meier
Table 3 HER2 expression in relation to main tumor cheracteristics and treatment response

\begin{tabular}{|c|c|c|c|c|}
\hline & & HER2 & oressio & \\
\hline & Total & Low & High & $p$ value \\
\hline Age & & & & \\
\hline$<55$ yrs & 18 & 13 & 5 & n.s. \\
\hline$\geq 55 \mathrm{yrs}$ & 18 & 14 & 4 & \\
\hline ER expressio & & & & \\
\hline Negative & 14 & 10 & 4 & n.s. \\
\hline Positive & 22 & 17 & 5 & \\
\hline PgR expressi & & & & \\
\hline Negative & 13 & 9 & 4 & n.s. \\
\hline Positive & 23 & 18 & 5 & \\
\hline Grading $^{\#}$ & & & & \\
\hline G2 & 21 & 18 & 3 & 0.05 \\
\hline G3 & 15 & 8 & 7 & \\
\hline Stage ${ }^{* \circ}$ & & & & \\
\hline$|-| \mid A$ & 17 & 16 & 1 & 0.003 \\
\hline$\|B-\|||$ & 16 & 8 & 8 & \\
\hline Ki67 & & & & \\
\hline Negative & 22 & 18 & 4 & n.s. \\
\hline Positive & 14 & 9 & 5 & \\
\hline Treatment re & & & & \\
\hline$C R+P R$ & 15 & 9 & 6 & 0.046 \\
\hline$S D+P D$ & 21 & 18 & 3 & \\
\hline
\end{tabular}

"IHC $0,1+$ and $2+$ FISH negative were regarded as negative while $\mathrm{IHC} 3+$ or 2+ FISH positive were regarded as positive. " According to Elston and Ellis classification (see text for complete reference). *According to UICC-TNM classification of malignant tumours, sixth edition $2002 .{ }^{\circ} \mathrm{At}$ initial diagnosis time. n.s. $=$ not significant; $C R=$ complete response; $P R=$ partial response; $\mathrm{SD}=$ stable disease; $\mathrm{PD}=$ disease progression.

survival analysis did not show a significant separation between HER2 positive and negative groups (Figure 3 for OS curves). The same results for both study molecules were obtained even incorporating in responders group patients achieving SD (not shown). Neither HER2 expression nor p53 status were independent predictors of OS and TTS at Cox regression analysis.

Lastly, we also observed at cross-tabulation analysis a clear correlation between HER2 testing with IHC and FISH $(p=0.001)$. Mean \pm SD FISH values in negative and positive groups were $1.51 \pm 0.223$ and $13.09 \pm 9.98$ respectively.

\section{Discussion}

Some preliminary comments about study limitations will facilitate the discussion of the results. First, presented data originate from a retrospective analysis that is naturally exposed to selection bias. Second, the relative small sample size could reduce the strength of statistical associations and dramatically affects survival analyses. Third, all patients did not receive the same chemotherapy regimen both in term of schedule (weekly or every 3 weeks administrations) and in term of associated drug (5 patient 


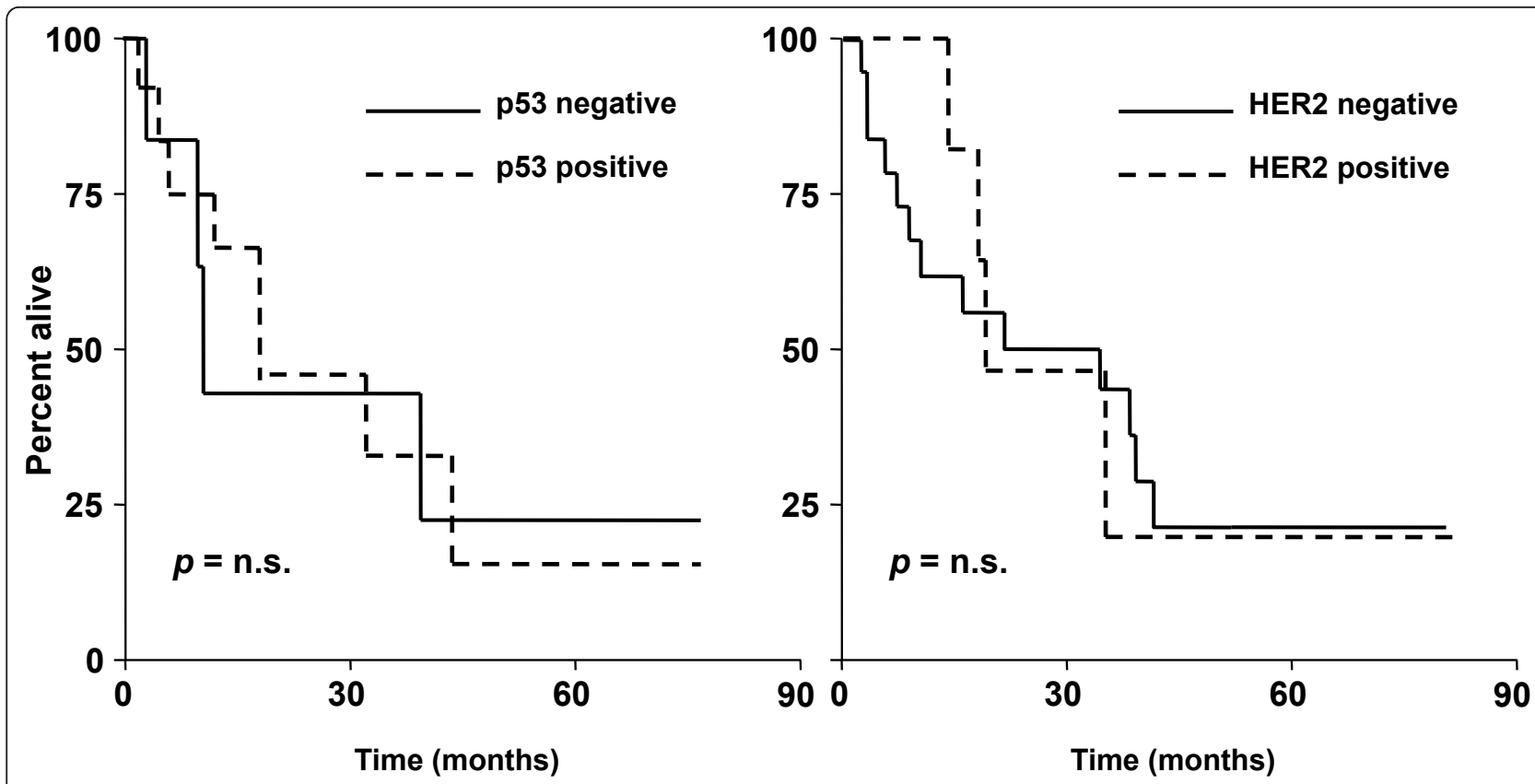

Figure 3 Kaplan-Meier curves for overall survival according to p53 or HER2 status. Kaplan-Meier curves for overall survival showed nosignificant separation between high vs low-espressors group for both p53 (left panel) and HER2 (right panel). Similar results were obtained for disease-free survival (not shown).

received an association of docetaxel plus capecitabine). Lastly, according to guidelines all HER2 positive patients (both patients that achieve a response and patients who did not) received trastuzumab while negative-ones were treated with docetaxel (alone or in combination). The difference in treatment received and, notably, in the underlying cancer biology makes HER2 positive and negative groups as different populations so affecting our data interpretation.

Within that specific experimental context, IHC-assessed nuclear p53 status failed to show any significant association with outcome and survival parameters. In fact, nuclear expression level of p53 did not differ between responders and not-responders patients. Reasons for this phenomenon cannot be limited to the above mentioned study limitations, probably, should be seek in the mechanisms of action (MoA) of docetaxel and, to a lesser extent, in technical limitations of p53 determination by IHC.

Docetaxel, a semi-synthetic analogue of paclitaxel, is a promoter of microtubule stabilization by direct binding leading to cell cycle arrest at $\mathrm{G} 2 / \mathrm{M}$ and apoptosis [33-35]. The $\beta$-subunit of the tubulin heterodimer, the key component of cellular microtubules, represent the molecular target of docetaxel [36]. This unique MoA could offer a putative explanation for the lack of association between p53 status and docetaxel sensitivity. In fact, docetaxel is not a direct DNA-damaging drug and docetaxel-induced cell cycle arrest occurs in a late phase of cell cycle (G2/M transition).
Conversely, p53 mainly (but not exclusively) acts in early phases of cell cycle inducing, after DNA damage, a G1 arrest by transactivation of p21Waf1/Cip1, a cyclindependent kinase inhibitor [37-39]. Therefore, the subcellular localization of docetaxel molecular target and the timing of docetaxel action during cell cycle do not overlap with those of p53 and this could explain, at least in part, our negative results. Some opposite data were published some years ago about a possible predictive role of TP53 mutation on paclitaxel sensitivity in breast cancer [22,23]; Johnson et al [23] proposed a model in which the loss of p53 function reduced the G1 block thus enhancing the efficacy of paclitaxel during mitosis. Our data do not support this hypothesis even accounting for docetaxel over paclitaxel differences.

Lastly, the correlation between p53 nuclear storage measured by IHC and p 53 mutation detected by sequencing has been estimated to be less than $75 \%$ in breast carcinomas [40]. Indeed, not all mutations yield a stable protein, and some mutations lead to an abnormal protein not detected by IHC. On the other hand, wild-type p53 may accumulate in some tumors as a result of the response to DNA damage, giving a positive IHC result not accounting for TP53 mutation [41].

On the other hand, we observed a clear predictive value for HER2 status. Patients with HER2-positive tumors were more likely to respond to docetaxel treatment even taking into account the small sample size. This observation seems to be true independently of 
patient category (HER2-positive or negative); in fact, in both the whole population and in HER2 subgroups it seems that the higher is the FISH value the higher is the probability to respond to docetaxel. In our opinion, the most likely explanation of our data may resides in the higher proliferation rate of this subset of cancers [25]. Docetaxel, as near-all chemotherapeutic agents, works better in tumors with an higher proliferation index because cancer growth-rate it's "per se" the main determinant of cell sensitivity to non-target chemoterapy. Moreover, rapid growth cancers (as HER2 positive breast cancer) have a greater percentage of cells in the $\mathrm{M}$ phase of cell cycle and this could represent another element to take into account.

More specific molecular mechanisms, i.e. as for topoisomerase II alpha, are unlikely. In fact, $\beta$-tubulin consists of six isotypes, all of which have related aminoacid sequences and are well conserved between species. Class I- $\beta$ tubulin is the most commonly expressed isotype in human beings, and the most common isotype in cancer cells [42]. The class-I isotype is encoded by the TUBB gene located at 6p2513 far from HER2 gene located on chromosome 17. Thus a co-amplification phenomenon is difficult to propose [42].

\section{Conclusions}

FISH-determined HER2 status may predict docetaxel sensitivity in metastatic breast cancer and could be an element to evaluate in the pre-treatment work-up. Obviously, a further prospective validation on a larger sample size is warranted before any possible clinical application. Interestingly, HER2 is a well-known predictor of trastuzumab efficacy and the association of trastuzumab plus taxanes can be considered as a standard of care in the first-line setting, so the possibility to predict treatment response by analysing one parameter (HER2) could be an attractive option.

Conversely, p53 status lack of any significant association with docetaxel sensitivity in the same setting. Probably, TP53 gene mutational analysis could be more informative that IHC, even if a simplistic association between TP53 gene status and taxane treatment response seem to be unlikely given the wide and very complicated molecular pathway related to p53.

\section{Author details}

'Oncology Department, Medical Oncology Division, AUSL12 di Viareggio and Istituto Toscano Tumori - Versilia Hospital, Lido di Camaiore, Italy. ${ }^{2}$ Oncology Department, Pathology Division, AUSL12 di Viareggio and Istituto Toscano Tumori - Versilia Hospital, Lido di Camaiore, Italy. ${ }^{3}$ Pathology Division, AUSL 1 Massa-Carrara and Istituto Toscano Tumori, Carrara, Italy.
}

\section{Authors' contributions}

AC: study design, statistical analysis, data interpretation and paper writing

SD: data collection and interpretation; PV: data collection,

immunohistochemistry performance and interpretation; OS: data interpretation and paper writing; CP: study design and statistical analysis; GT: data collection and interpretation; CV: data interpretation and paper writing; FDL: data collection, immunohistochemistry performance and interpretation; LM: data collection, immunohistochemistry performance and interpretation; AC: FISH performance and interpretation, data collection; DA: study design, data interpretation and paper writing. All authors read and approved the final manuscript.

\section{Competing interests}

The authors declare that they have no competing interests.

Received: 30 November 2010 Accepted: 11 April 2011

Published: 11 April 2011

\section{References}

1. Jemal A, Siegel R, Ward E, Hao Y, Xu J, Murray T, Thun MJ: Cancer statistics, 2008. CA Cancer J Clin 2008, 58:71-96.

2. Grande $E$, Inghelmann $R$, Francisci $S$, Verdecchia A, Micheli A, Baili P, Capocaccia R, De Angelis R: Regional estimates of breast cancer burden in Italy. Tumori 2007, 93:374-9.

3. Sledge GW, Neuberg D, Bernardo P, Ingle JN, Martino S, Rowinsky EK, Wood WC: Phase III trial of doxorubicin, paclitaxel, and the combination of doxorubicin and paclitaxel as front-line chemotherapy for metastatic breast cancer: an Intergroup trial (E1193). J Clin Oncol 2003, 21:588-592.

4. De Laurentiis M, Cancello G, D'Agostino G, Giuliano M, Giordano A Montagna E, Lauria R, Forestieri V, Esposito A, Silvestro L, Pennacchio R, Criscitiello C, Montanino A, Limite G, Bianco AR, De Placido S: Taxanebased combinations as adjuvant chemotherapy of early breast cancer: a meta-analysis of randomized trials. J Clin Oncol 2008, 26:44-53.

5. Lane DP: p53, guardian of the genome. Nature 1992, 358:15-16.

6. Levine AJ: p53, the cellular gatekeeper for growth and division. Cell 1997, 88:323-331.

7. Zilfou JT, Lowe SW: Tumor Suppressive Functions of p53. Cold Spring Harb Perspect Biol 2009, 1:a001883.

8. Yee KS, Vousden $\mathrm{KH}$ : Complicating the complexity of p53. Carcinogenesis 2005, 26:1317-1322.

9. Riley $\mathrm{T}$, Sontag $\mathrm{E}$, Chen P, Levine A: Transcriptional control of human p53regulated genes. Nat Rev Mol Cell Biol 2008, 9:402-412.

10. Green DR, Kroemer G: Cytoplasmic functions of the tumour suppressor p53. Nature 2009, 458:1127-1130.

11. Petitjean A, Mathe E, Kato S, Ishioka C, Tavtigian SV, Hainaut P, Olivier M: Impact of mutant p53 functional properties on TP53 mutation patterns and tumor phenotype: lessons from recent developments in the IARC TP53 database. Hum Mutat 2007, 28:622-629.

12. Soussi T, Ishioka C, Claustres M, Béroud C: Locus-specific mutation databases: pitfalls and good practice based on the p53 experience. Nat Rev Cancer 2006, 6:83-90.

13. Vousden $\mathrm{KH}$, Prives $\mathrm{C}$ : $\mathrm{p} 53$ and prognosis: new insights and further complexity. Cell 2005, 120:7-10.

14. Lønning PE, Knappskog S, Staalesen V, Chrisanthar R, Lillehaug JR: Breast cancer prognostication and prediction in the postgenomic era. Ann Oncol 2007, 18:1293-1306.

15. Lacroix M, Toillon RA, Leclercq G: p53 and breast cancer, an update. Endocr Relat Cancer 2006, 13:293-325.

16. Geisler S, Lønning PE, Aas T, Johnsen H, Fluge O, Haugen DF, Lillehaug JR, Akslen LA, Børresen-Dale AL: Influence of TP53 gene alterations and cerbB-2 expression on the response to treatment with doxorubicin in locally advanced breast cancer. Cancer Res 2001, 61:2505-2512.

17. Abdel-Fatah TM, Powe DG, Agboola J, Adamowicz-Brice M, Blamey RW, Lopez-Garcia MA, Green AR, Reis-Filho JS, Ellis IO: The biological, clinical and prognostic implications of p53 transcriptional pathways in breast cancers. J Pathol 2010, 220:419-434

18. Sayeed A, Konduri SD, Liu W, Bansal S, Li F, Das GM: Estrogen receptor a inhibits p53 mediated transcriptional repression: implications for the regulation of apoptosis. Cancer Res 2007, 67:7746-7755.

19. Veerakumarasivam A, Scott HE, Chin SF, Warren A, Wallard MJ, Grimmer D, Ichimura K, Caldas C, Collins VP, Neal DE, Kelly JD: High resolution arraybased comparative genomic hybridization of bladder cancers identifies mouse double minute 4 (MDM4) as an amplification target exclusive of MDM2 and PT53. Clin Cancer Res 2008, 14:2527-2534. 
20. Ding SL, Sheu LF, Yu JC, Yang TL, Chen BF, Leu FJ, Shen CY: Abnormality of the DNA double strand-break checkpoint/repair genes, ATM, BRCA1 and TP53, in breast cancer is related to tumour grade. Br J Cancer 2004, 90:1995-2001.

21. Rahko E, Blanco G, Bloigu R, Soini Y, Talvensaari-Mattila A, Jukkola A: Adverse outcome and resistance to adjuvant antiestrogen therapy in node-positive postmenopausal breast cancer patients - the role of $\mathrm{p} 53$ Breast 2006, 15:69-75.

22. Kandioler-Eckersberger $D$, Ludwig C, Rudas M, Kappel S, Janschek E, Wenzel C, Schlagbauer-Wadl H, Mittlböck M, Gnant M, Steger G, Jakesz R: TP53 mutation and p53 overexpression for prediction of response to neo-adjuvant treatment in breast cancer patients. Clin Cancer Res 2000, 6:50-56.

23. Johnson KR, Fan W: Reduced expression of $\mathrm{p} 53$ and $\mathrm{p} 21 \mathrm{WAF} 1 / \mathrm{CIP} 1$ sensitizes human breast cancer cells to paclitaxel and its combination with 5-fluorouracil. Anticancer Res 2002, 22:3197-3204.

24. Noguchi S: Predictive factors for response to docetaxel in human breast cancers. Cancer Sci 2006, 97:813-820.

25. Slamon DJ, Clark GM, Wong SG, Levin WJ, Ullrich A, McGuire WL: Human breast cancer: correlation of relapse and survival with amplification of the HER-2/neu oncogene. Science 1987, 235:177-182.

26. Yakes FM, Chinratanalab W, Ritter CA, King W, Seelig S, Arteaga CL: Herceptin-induced inhibition of phosphatidylinositol-3 kinase and Akt is required for antibody-mediated effects on p27, cyclin D1, and antitumor action. Cancer Res 2002, 62:4132-4141.

27. Morrow PKH, Zambrana F, Esteval FJ: Advances in systemic therapy for HER2-positive metastatic breast cancer. Breast Cancer Res 2009, 11:207.

28. Garnock-Jones KP, Keating GM, Scott LJ: Trastuzumab: a review of its use as adjuvant treatment in human epidermal growth factor receptor 2 (HER2)-positive early breast cancer. Drugs 2010, 70:215-39.

29. Gennari A, Sormani MP, Pronzato P, Puntoni M, Colozza M, Pfeffer U, Bruzzi P: HER2 status and efficacy of adjuvant anthracyclines in early breast cancer: A pooled analysis of randomized trials. J Natl Cancer Inst 2008, 100:14-20.

30. Sobin LH, Wittekind C: UICC TNM Classification of Malignant Tumours. New York: Wiley-Liss; 62002

31. Elston C, Ellis I: Pathological prognostic factors in breast cancer. I. The value of histologic grade in breast cancer: experience from a large study with long-term follow-up. Histopatology 1991, 19:403-10

32. The World Health Organization: Histological typing of breast tumors. Neoplasma 1983, 30:113-23.

33. Clarke SJ, Rivory LP: Clinical pharmacokinetics of docetaxel. Clin Pharmacokinet 1999, 36:99-114

34. Schiff PB, Fant J, Horwitz SB: Promotion of microtubule assembly in vitro by taxol. Nature 1979, 277:665-67.

35. Ganansia-Leymarie V, Bischoff P, Bergerat JP, Holl V: Signal transduction pathways of taxanes-induced apoptosis. Curr Med Chem Anti-Canc Agents 2003, 3:291-306

36. Verweij JM, Clavel M, Chevalier B: Paclitaxel (Taxol ${ }^{\mathrm{TM}}$ ) and docetaxe (Taxotere ${ }^{\mathrm{TM}}$ ): Not simply two of a kind. Ann Oncol 1994, 5:495-505.

37. Brugarolas J, Chandrasekaran C, Gordon Jl, Beach D, Jacks T, Hannon GJ: Radiation-induced cell cycle arrest compromised by p21 deficiency. Nature 1995, 377:552-557.

38. St Clair S, Manfredi Jj: The dual specificity phosphatase $\mathrm{Cdc} 25 \mathrm{C}$ is a direct target for transcriptional repression by the tumor suppressor p53. Cell Cycle 2006, 5:709-713.

39. Deng C, Zhang P, Harper JW, Elledge SJ, Leder P: Mice lacking p21CIP1/ WAF1 undergo normal development, but are defective in G1 checkpoint control. Cell 1995, 82:675-684.

40. Norberg T, Lennerstrand J, Inganas M, Bergh J: Comparison between p53 protein measurements using the luminometric immunoassay and immunohistochemistry with detection of p53 gene mutations using CDNA sequencing in human breast tumors. Int J Cancer 1998, 79:376-383.

41. Bertheau $P$, Espiè $M$, Turpin E, Lehmann J, Plassa LF, Varna $M$, Janin $A$, de Thè H: TP53 status and response to chemotherapy in breast cancer. Pathobiology 2008, 75:132-139.

42. Berrieman HK, Lind MJ, Cawkwell L: Do $\beta$-tubulin mutations have a role in resistance to chemotherapy? Lancet Oncol 2004, 5:158-64. doi:10.1186/1756-9966-30-38

Cite this article as: Camerini et al:: Evaluation of HER2 and p53 expression in predicting response to docetaxel-based first-line chemotherapy in advanced breast cancer. Journal of Experimental \& Clinical Cancer Research 2011 30:38.

\section{Submit your next manuscript to BioMed Central and take full advantage of:}

- Convenient online submission

- Thorough peer review

- No space constraints or color figure charges

- Immediate publication on acceptance

- Inclusion in PubMed, CAS, Scopus and Google Scholar

- Research which is freely available for redistribution

Submit your manuscript at www.biomedcentral.com/submit
Ciomed Central 